J Clin Epidemiol Vol. 50, No. 10, pp. 1069-1077, 1997

Copyright (c) 1997 Elsevier Science Inc.

\title{
Competing Causes of Death: A Death Certificate Study
}

\author{
J. P. Mackenbach,,$^{1,}$ A. E. Kunst, ${ }^{1}$ H. Lautenbach, ${ }^{1}$ Y. B. Oei, ${ }^{2}$ and F. Bijlsma ${ }^{2}$ \\ ${ }^{1}$ Department of Public Health, Erasmus University, Rotterdam, The Netherlands; and \\ ${ }^{2}$ Division of Health and Soctal Well-being, Statistics Netherlands, Voorburg, The Netherlands
}

\begin{abstract}
Background: Despite the widespread interest in competing causes of death, empirical information on interrelationships between causes of death is scarce. We have used death certificate information to estimate the prevalence of competing causes of death at the moment of dying from specific underlying causes of death. Materials and Methods: In a stratified sample of 5975 deaths occurring in The Netherlands in 1990, information contained in the death certificate was used to determine the presence of diseases which, in the hypothetical case of elimination of the underlying cause of death, could develop into a new underlying cause of death. Poisson regression analysis was used to describe variation in age- and sex-adjusted prevalence of competing causes of death between different underlying causes. Results: Pcr 100 deaths, 46.2 competing causes were identified (52.0 after reweighting to take away the effects of stratification). The most frequent competing causes, all occurring in more than $2 \%$ of deaths, were: senile dementia, diabetes mellitıs, ischemic heart disease, cerebrovascular disease, chronic obstructive lung disease, hypertensive disease, and arteriosclerosis. The overall prevalence of competing causes is relatively high among deaths from respiratory diseases (relative risk for respiratory diseases as compared with all underlying causes $(R R)=1.42(95 \% \mathrm{CI}, 1.25-1.62)$ ), relatively low among deaths from neoplasms ( $R R=0.54(95 \% \mathrm{CI}, 0.47-0.62)$ ), and in between among deaths from cardiovascular diseases (RR $=1.08$ (95\% CI, 0.95-1.22)). Conclusion: Although it cannot be excluded that some of the variation in prevalence of competing causes by underlying cause is due to selective underregistration of coexisting diseases on death certificatcs, the results of this study suggest that conventional estimates of gains in life expectancy after elimination of neoplasms are much less biased by the effect of competing causes than the corresponding estimates for cardiovascular diseases and particularly respiratory diseases. J CLIN EPIDEMIOL 50;10:1069-1077, 1997. (C) 1997 Elsevier Science Inc.
\end{abstract}

KEY WORDS. Mortality, multiple cause, death certificate

\section{INTRODUCTION}

One of the aims of health care and public health interventions is to reduce mortality from a specific disease. An important problem in the estimation of the effect that this will have on total mortality and on life expectancy is related to the concept of "competing causes of death." This concept refers to the simple fact that different causes of death are in competition for the death of each person. As Chiang has pointed out: "Every human is continuously exposed to many risks of death, such as cancer, heart disease, and tuberculosis. Because death is not a repetitive event and is usually attributed to a single cause, these risks compete with each other for the life of a person" ([1], p. 281).

Naturally, a reduction of the number of deaths from one cause will, in the short or long run, produce an increase of

\footnotetext{
-Address for correspondence: Johan P. Mackenbach, Ph.D., Department of Public Health, Erasmus University, P.O. Box 1738, 3000 Dr Rotterdam, The Netherlands.

Accepted for publication on 8 July 1997.
}

the number of persons who die from competing causes. This phenomenon of substitution is due to an increase in the number of persons exposed to the risk of dying from competing causes of death. Estimations can be made of the effect on total mortality and life expectancy by assuming that those who are saved from the eliminated cause have agespecific rates of dying from other causes which are equal to those observed for the population as a whole [2-6]. Unfortunately, reality is more complex and simple substitution is not the only possible relationship between competing causes of death. Frequently, there will be dependency between causes of death, that is, persons who die from a specific cause will have higher (or lower) risks of dying from competing causes than are reflected in the average rates for the population as a whole [5-10]. This is likely to occur, for example, if the eliminated cause and a competing cause have one or more risk factors in common. In such cases, the effects on total mortality and life expectancy will be smaller (or larger) than one would expect under the assumption of simple substitution. Because the nature and strength 
of the associations with competing causes of death will differ between underlying causes of death, comparisons of effects on total mortality and life expectancy between different underlying causes of death are likely to be seriously biased.

While these general notions are well known among epidemiologists and demographers, empirical information which would allow the quantification of associations between causes of death is hardly available. One possible source of such information is routinely collected data on multiple causes of death, that is, on more than the underlying cause of death [11-20]. In a previous study we showed that multiple cause of death data can indeed be used to study these associations [21]. A major limitation of this previous study is, however, that we had to rely on the standard coding practices for other than the underlying cause of death. These standard coding practices do not take into account whether other diseases mentioned on the death certificate are eligible for developing into a new underlying cause of death if the underlying cause would be eliminated, and are therefore far from satisfactory for our purpose. In this article we report on a study in which the information present in a large sample of death certificates was recoded in order to estimate the prevalence of competing causes of death at the moment of dying from specific underlying causes of death. Our main purpose is to see whether this prevalence varies by underlying cause of death.

\section{MATERIALS AND METHODS}

Data on the prevalence of compering causes of death were obtained for a random sample of 5975 certificates for deaths occurring in The Netherlands in 1990. This sample was stratified by four broad groups of underlying causes of death: neoplasms ( $30 \%$ of the sample), cardiovascular diseases $(30 \%)$, respiratory diseases $(20 \%)$, and other diseases (20\%). Deaths due to ill-defined or external causes of death were excluded. The reason for exclusion of external causes is that their certification and coding differ considerably from those of "natural causes." Death certificates have a separate section for certifying external causes, and coding rules are also specific. This would have implied that we would have had to develop separate procedures for the recoding of competing causes present in persons dying of external causes, and that would have made our study too complicated. The sample was also stratified by age: $0-54(28 \%), 55-69$ $(28 \%), 70-79(24 \%)$, and $80+(19 \%)$. Younger age groups were over-represented in order to have sufficient numbers of deaths at younger ages and to be able to analyze age patterns. The stratification weights represent the share of each age group in the total number of potential years of life lost in The Netherlands in 1990.

The code for the underlying cause of death was taken from the cause-of-dcath registry. The rules for coding the underlying cause of death largely follow the $\mathrm{WHO}$ rules given in the 9th Revision of the International Classification of Diseases (ICD) [22].

Each death certificate was coded for the presence of competing causes of death. As a general rule, we considered a condition mentioned on the death certificate to be a competing cause of death if it met each of the following criteria:

1. The condition is apparently not a complication or side effect of the underlying, or of another identified competing, cause of death. In other words, the condition originated independently from other causes of death given on the certificate

2. The condition or its consequences has a long-lasting or chronic nature.

3. The condition has the potential to develop into a new underlying cause of death in the hypothetical case that the original underlying cause would be eliminated, or it has the potential to give rise to a disease that in turn could develop into a new underlying cause of death.

The first and third criteria specify the main characteristics of competing causes of death: independence from the underlying cause of death and the potential to become an underlying cause of death itself. The second criterion was added to exclude acute conditions such as influenza, whose presence implies an increased death risk for a short period only. The second part of the third criterion was added to include biological risk factors for disease, such as obesity and hypertension. Although these risks factors do not, or only rarely, become an underlying cause of death, their presence implies an increased risk for the development of other diseases which in turn could lead to death.

This general rule was then developed into a standardized and efficient procedure for recoding individual death certificates. A list was made of all conditions which are frequently mentioned on death certificates and which therefore had a high likelihood of occurring in the sample. This list included all conditions for which, in The Netherlands in 1990, at least 100 cases occurred as an underlying cause of death, and/or at least 35 as a multiple (non-underlying) cause of death. Each of the 135 conditions on this list was classified in one of three categories: (1) never to be coded as competing cause of death; (2) to be coded as a competing cause of death unless it appears from other information on the death certificate that it does not fulfill all criteria; and (3) risk factor for the development of a fatal disease, always to be coded as a competing cause of death. To make a decision on conditions in category 2 , the coders were allowed to use the following types of information on the death certificate: (1) the nature of the underlying cause of death; (2) the duration of the conditions mentioned on the death certificate; and (3) the sequence in which the conditions are mentioned on the death certificate. Before actually coding the 5975 death certificates, the coding procedure was tested on a test sample of 100 death certificates. Competing 
causes of death were classified according to the ICD-9 classification. The coding was carried out by two of the authors. All cases where any doubt occurred were discussed in order to reach a common opinion.

The main objective of the analysis reported in this article, was to compare the prevalence rates of competing causes of death between underlying causes of death. Because the prevalence of competing causes of death is age-dependent, and the age distribution of deaths differs between underly. ing causes, adjustment of the prevalence rates was necessary. Poisson regression analysis was carried out with occurrence of a competing cause of death as the dependent variable and underlying cause (four categories in the main analysis reported in this article), age (four groups: $0-54,55-69,70-$ 79 , and $80+)$, and sex as the independent variables. Because there are no natural reference categories for comparing prevalences of competing causes, all relative risks (RR) were calculated with the prevalence of the competing cause in the whole sample as the reference value. In addition to calculating $95 \%$ confidence intervals (CI), the overall statistical significance of variation in prevalence of a competing causc by undcrlying cause was assessed by adding this variable to a model already containing age and sex, and by comparing the resulting decrease in scaled deviance (given the loss of 3 degrees of freedom) with the chi-square distribution. The regression analyses were carried out with the GLIM package.

\section{RESULTS}

In the sample of 5975 certificates, 2762 competing causes of death were identified. This corresponds to 46.2 competing causes per 100 deaths. Because the sample was stratified by underlying cause and age, reweighting is necessary in order to estimate the prevalence of competing causes among all deaths in The Netherlands. After reweighting on the basis of the national distribution of deaths by underlying cause (excluding ill-defined and external causes) and age the prevalence is 52.0 competing causes per 100 deaths.

The variation in overall prevalence of competing causes by age, sex, and underlying cause of death is illustrated in Fig. 1. The prevalence of competing causes of death increases up to the age group 70-79 years but then remains approximately constant. For each age group, prevalence rates are low for deaths from neoplasms, intermediate for deaths from cardiovascular diseases, and high for deaths from respiratory diseases. The pattern by age and underlying cause of death is nearly identical for males and females.

Prevalence figures for specific competing causes of death are given in Table 1. For this table, competing causes of death were grouped into 37 categories which were important as competing cause of death (identified more than 20 times in the sample) and/or as underlying causc of death (more than 1000 deaths in The Netherlands in 1990).
Competing causes which were identified for more than $2 \%$ of all deaths are (in order of frequency): senile dementia, diabetes mellitus, ischemic heart disease, cerebrovascular disease, chronic obstructive lung disease, hypertensive disease, and arteriosclerosis. Although the overall prevalence of competing causes as resulting from our special coding exercise is identical to that resulting from routine coding (ratio routine/special coding $=1.00$ ), important discrepancies can be observed at the level of specific conditions. Competing causes for which the prevalence is seriously underestimated by routine coding (ratio routine/special coding $<0.50$ ) include frequent conditions such as diabetes mellitus, senile dementia, and arteriosclerosis. On the other hand, routine coding seriously overestimates (ratio $>2.00$ ) the prevalence of certain other competing causes of death, particularly conditions which are frequently certified as "immediate" causes of death such as pneumonia and influenza and other diseases of the respiratory system.

For further analysis, the 37 categories presented in Table 1 were combined into 12 groups with each group having more than 50 codings as competing cause of death. Table 2 presents information on variation by age group in the prevalence of these 12 groups of competing causes. Various age patterns are observed. Most competing causes of death have their peak prevalence in the 70-79 year age group, but diabetes mellitus, senile dementia, chronic obstructive lung disease, and nephritis and nephrosis have their highest prevalence above age 80 . The single exception on the general rule of higher prevalences in older age groups is alcoholism, which as a competing cause of death is more frequent in the younger age groups.

Men and women have largely similar prevalences of competing causes of death (after controlling for differences inage distribution and underlying cause of death). There is a tendency for alcoholism, ischemic heart disease, and chronic obstructive lung disease to be more frequent among men, and for senile dementia to be more frequent among women (detailed results not shown).

Variation in age- and sex-adjusted prevalence of competing causes by main group of underlying cause of death is presented in Table 3. The overall prevalence of competing causes is highest for respiratory diseases ( $R R=1.42$ (95\% CI: $1.25-1.62)$ ). This is the result of RRs exceeding 1 for many specific competing causes, but particularly senile dementia, other cardiovascular disease, and nephritis and nephrosis. Among deaths due to neoplasms as an underlying cause of death, the prevalence of competing causes is relatively low (for all competing causes together, $\mathrm{RR}=0.54$ (95\% CI: 0.47-0.62)). The RRs for all specific competing causes of death are below 1 , with the exception of other cancers (RR - 1.09 (95\% CI: 0.49-2.41)). The prevalence of competing causes among deaths due to cardiovascular discases as an underlying cause of death generally is close to the average for the whole sample, with the exception of the 

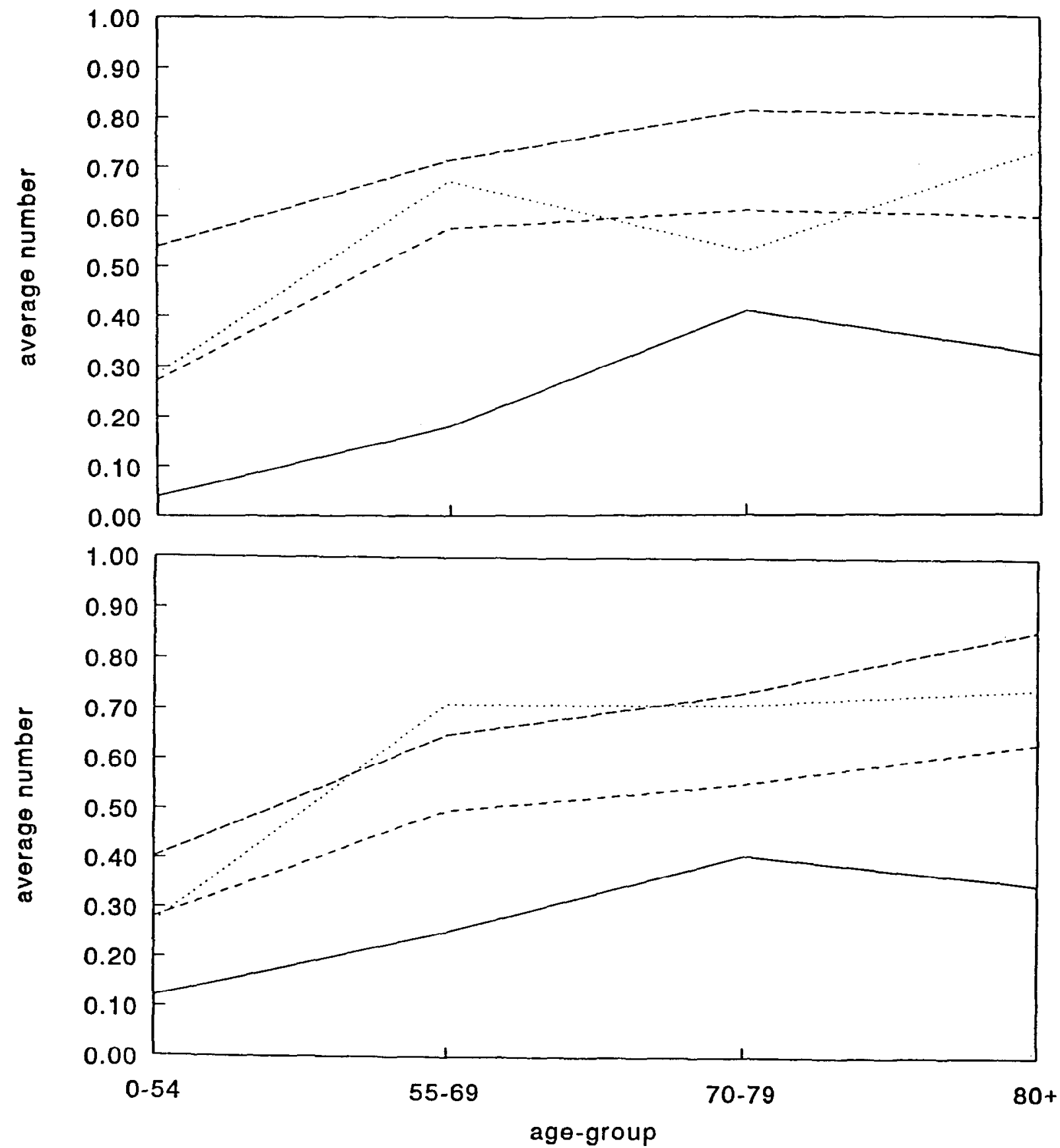

\section{neoplasm -... cardiovas - - respirator $\cdots . . . \cdots$ other}

FIGURE 1. Average number of competing causes of death per death, by age group and by underlying cause of death, The Netherlands, sample, 1990. Men (upper graph), women (lower graph).

higher prevalences of certain precursors such as hypertensive disease $(\mathrm{RR}=2.70(95 \% \mathrm{CI}: 1.73-4.21)$ ).

Sample size in general does not permit studying associations between specific underlying causes of death and specific competing causcs of death. For some rclatively frequent underlying causes of death, however, we were able to check whether associations which could be expected on the basis of common risk factors, could indeed be found in our material (Table 4). On the basis of common relationships with smoking, associations could be expected to occur between, for example, lung cancer as an underlying cause of death and two out of the 12 groups of competing causes of death, ischemic heart disease and chronic obstructive lung disease. Given the very low RRs found for all neoplasms (Table 3), 
TABLE 1. Prevalence of competing causes of death (The Netherlands, sample, 1990)

\begin{tabular}{|c|c|c|c|c|}
\hline Competing cause of death & $\begin{array}{l}\text { ICD.9 } \\
\text { code }\end{array}$ & $\begin{array}{c}\text { Number of } \\
\text { mentions } \\
\text { in sample }\end{array}$ & $\begin{array}{l}\text { Per } 100 \text { deaths } \\
\text { in sample }\end{array}$ & $\begin{array}{l}\text { Ratio routine/ } \\
\text { special coding }\end{array}$ \\
\hline Stomach cancer & 151 & 4 & 0.06 & 1.00 \\
\hline Colon cancer & $153-154$ & 15 & 0.25 & 0.86 \\
\hline Pancreas cancer & 157 & 1 & 0.01 & 1.00 \\
\hline Lung cancer & 162 & 19 & 0.31 & 0.73 \\
\hline Breast cancer & 174 & 10 & 0.16 & 1.11 \\
\hline Prostatc canccr & 185 & 10 & 0.16 & 0.90 \\
\hline Bladder cancer & 188 & 8 & 0.13 & 0.87 \\
\hline M.n. of lymphatic tissue & $200-208$ & 21 & 0.35 & 1.04 \\
\hline Other neoplasms & $R(140-239)$ & 37 & 0.61 & 0.89 \\
\hline Hypothyroidism & $243-244$ & 19 & 0.31 & 0.26 \\
\hline Diabetes mellitus & 250 & 244 & 4.08 & 0.38 \\
\hline Obesity & 278 & 36 & 0.60 & 0.94 \\
\hline Anemia & $280-285$ & 32 & 0.53 & 0.31 \\
\hline Senile dementia & 290 & 283 & 4.73 & 0.01 \\
\hline Alcoholism & 303 & 79 & 1.32 & 0.54 \\
\hline Parkinson's disease & 332 & 43 & 0.71 & 0.95 \\
\hline Epilepsy & 345 & 21 & 0.35 & 0.14 \\
\hline Hypertensive disease & $401-405$ & 149 & 2.49 & 0.95 \\
\hline Ischemic heart disease & $410-414$ & 199 & 3.33 & 1.00 \\
\hline Chronic pulmonary heart disease & 416 & 114 & 1.90 & 1.74 \\
\hline Other diseases of endocardium & 424 & 17 & 0.28 & 0.64 \\
\hline Cardiac dysrhythmias & 427 & 84 & 1.40 & 0.03 \\
\hline Heart failure & 428 & 48 & 0.80 & 0.02 \\
\hline Other heart diseases & $R(390-429)$ & 65 & 1.08 & 1.64 \\
\hline Cerebrovascular disease & $430-438$ & 185 & 3.09 & 0.54 \\
\hline Arteriosclerosis & 440 & 125 & 2.09 & 0.16 \\
\hline Aneurysm & $441-442$ & 11 & 0.18 & 0.54 \\
\hline Other vascular disease & $443-459$ & 30 & 0.50 & 1.53 \\
\hline Pneumonia and influenza & $480-487$ & 0 & 0.00 & $\infty$ \\
\hline Chronic obstructive lung disease & $490-496$ & 173 & 2.89 & 0.97 \\
\hline Other diseases of respiratory system & $R(460-519)$ & 12 & 0.20 & 5.83 \\
\hline Peptic ulcer & $531-533$ & 22 & 0.36 & 1.04 \\
\hline Chronic liver disease and cirrhosis & 571 & 26 & 0.43 & 1.03 \\
\hline Nephritis, nephrosis & $580 \quad 589$ & 82 & 1.37 & 0.26 \\
\hline Disease of urinary system & 599 & 32 & 0.53 & 1.40 \\
\hline Hypertensia of prostate & 600 & 20 & 0.33 & 0.50 \\
\hline Rheumatoid arthritis & 714 & 38 & 0.63 & 0.63 \\
\hline Other diseases & $R(001-799)$ & 448 & 7.49 & 1.63 \\
\hline All & $001-799$ & 2762 & 46.22 & 1.00 \\
\hline
\end{tabular}

"Ratio of the number of times a code was assigned during routine coding and the number of times a code was assigned during special coding.

the two RRs above 1 found for ischemic heart disease and chronic lung disease among persons dying from lung cancer (Table 4) are clearly in accordance with this expectation. The same applies to the other patterns of association documented in Table 4.

\section{DISCUSSION}

Despite the widespread interest in compering causes of death, empirical information on interrelationships between causes of dcath is scarce. This study exploits the usefulness of one widely available source of information-death certificates-which not only registers the underlying cause of death and more immediate causes, but often in addition contains information on the presence of other diseases at the moment of death. We coded a sample of 5975 death certificates for the presence of diseases which according to a set of explicit rules could be considered as competing causes of death. The prevalence of such diseases was found to vary strongly by underlying cause of death. In general, relatively few competing causes of death were observed among deaths from neoplasms, and relatively many among deaths from respiratory diseases.

In a previous study we compared the prevalence of competing causes between underlying causes of death on the basis of multiple cause codes as assigned during routine cod- 
TABLE 2. Variation by age group in the prevalence of competing causes of death (The Netherlands, sample, 1990)

\begin{tabular}{|c|c|c|c|c|c|}
\hline \multirow[b]{2}{*}{ Competing cause of death ${ }^{a}$} & \multicolumn{4}{|c|}{ RR $(95 \% \text { CI })^{b}$ by age group } & \multirow[b]{2}{*}{$\begin{array}{c}\text { Significance } \\
\text { level }^{c}\end{array}$} \\
\hline & $\begin{array}{c}0-54 \\
n=1647 \\
\end{array}$ & $\begin{array}{c}55-69 \\
n=1699 \\
\end{array}$ & $\begin{array}{c}70-79 \\
n=1456\end{array}$ & $\begin{array}{c}80+ \\
n=1173 \\
\end{array}$ & \\
\hline Neoplasms & $\begin{array}{c}0.21 \\
(0.10-0.47)\end{array}$ & $\begin{array}{c}1.36 \\
(0.93-1.99)\end{array}$ & $\begin{array}{c}1.45 \\
(0.94-2.22)\end{array}$ & $\begin{array}{c}1.10 \\
(0.64-1.88)\end{array}$ & $* *$ \\
\hline Diabetes mellitus & $\begin{array}{c}0.16 \\
(0.08-0.33)\end{array}$ & $\begin{array}{c}1.22 \\
(0.87-1.70)\end{array}$ & $\begin{array}{c}1.76 \\
(1.24-2.50)\end{array}$ & $\begin{array}{c}1.83 \\
(1.23-2.71)\end{array}$ & $* *$ \\
\hline Senile dementia & $\begin{array}{c}0.11 \\
(0.04-0.32)\end{array}$ & $\begin{array}{c}0.63 \\
(0.36-1.12)\end{array}$ & $\begin{array}{c}2.32 \\
(1.43-3.76)\end{array}$ & $\begin{array}{c}4.63 \\
(2.83-7.57)\end{array}$ & $* *$ \\
\hline Alcoholism & $\begin{array}{c}1.51 \\
(0.64-3.54)\end{array}$ & $\begin{array}{c}1.12 \\
(0.47-2.63)\end{array}$ & $\begin{array}{c}0.23 \\
(0.07-0.73)\end{array}$ & $\begin{array}{c}0.14 \\
(0.04-0.58)\end{array}$ & ** \\
\hline Hypertensive disease & $\begin{array}{c}0.74 \\
(0.40-1.37)\end{array}$ & $\begin{array}{c}1.26 \\
(0.73-2.17)\end{array}$ & $\begin{array}{c}0.92 \\
(0.51-1.68)\end{array}$ & $\begin{array}{c}0.69 \\
(0.35-1.36)\end{array}$ & ${ }^{*}$ \\
\hline Ischemic heart disease & $\begin{array}{c}0.30 \\
(0.17-0.50)\end{array}$ & $\begin{array}{c}1.41 \\
(1.02-1.95)\end{array}$ & $\begin{array}{c}1.22 \\
(0.84-1.78)\end{array}$ & $\begin{array}{c}1.16 \\
(0.75-1.79)\end{array}$ & $* *$ \\
\hline Cerebrovascular disease & $\begin{array}{c}0.12 \\
(0.05-0.30)\end{array}$ & $\begin{array}{c}1.30 \\
(0.81-2.09)\end{array}$ & $\begin{array}{c}1.75 \\
(1.08-2.85)\end{array}$ & $\begin{array}{c}1.53 \\
(0.89-2.62)\end{array}$ & ** \\
\hline Arteriosclerosis & $\begin{array}{c}0.26 \\
(0.11-0.63)\end{array}$ & $\begin{array}{c}1.40 \\
(0.75-2.62)\end{array}$ & $\begin{array}{c}1.39 \\
(0.72-2.71)\end{array}$ & $\begin{array}{c}1.22 \\
(0.59-2.52)\end{array}$ & ** \\
\hline Other cardiovascular diseases & $\begin{array}{c}0.30 \\
(0.17-0.52)\end{array}$ & $\begin{array}{c}1.13 \\
(0.77-1.68)\end{array}$ & $\begin{array}{c}1.67 \\
(1.12-2.47)\end{array}$ & $\begin{array}{c}1.62 \\
(1.06-2.47)\end{array}$ & $* *$ \\
\hline Chronic obstructive lung disease & $\begin{array}{c}0.22 \\
(0.12-0.42)\end{array}$ & $\begin{array}{c}1.12 \\
(0.80-1.57)\end{array}$ & $\begin{array}{c}1.62 \\
(1.15-2.30)\end{array}$ & $\begin{array}{c}1.68 \\
(1.10-2.55)\end{array}$ & ** \\
\hline Nephritis and nephrosis & $\begin{array}{c}0.73 \\
(0.24-2.20)\end{array}$ & $\begin{array}{c}0.92 \\
(0.32-2.65)\end{array}$ & $\begin{array}{c}1.40 \\
(0.49-4.01)\end{array}$ & $\begin{array}{c}1.76 \\
(0.60-5.19)\end{array}$ & * \\
\hline All other diseases & $\begin{array}{c}0.96 \\
(0.76-1.22)\end{array}$ & $\begin{array}{c}1.02 \\
(0.82-1.28)\end{array}$ & $\begin{array}{c}1.04 \\
(0.82-1.32)\end{array}$ & $\begin{array}{c}0.89 \\
(0.68-1.17)\end{array}$ & NS \\
\hline All & $\begin{array}{c}0.54 \\
(0.47-0.63)\end{array}$ & $\begin{array}{c}1.15 \\
(1.03-1.28)\end{array}$ & $\begin{array}{c}1.35 \\
(1.20-1.53)\end{array}$ & $\begin{array}{c}1.41 \\
(1.24-1.61)\end{array}$ & $* *$ \\
\hline
\end{tabular}

Abbreviations: $\mathrm{CI}=$ confidence interval, $\mathrm{NS}=$ not significant, $\mathrm{RR}=$ relative risk.

${ }^{a}$ For ICD-9 codes, see Table 1 .

${ }^{b}$ Ratios of the prevalence in a certain age-group and the prevalence in the whole sample, controlling for sex and underlying cause.

"Test based on reduction in scaled deviance following introduction of "age" into a regression model already containing sex and underlying cause.

NS $=p \geq 0.05$.

${ }^{*} p<0.05$.

$* 0<0.01$

ing by Statistics Netherlands [21]. The rules used in routine coding do not aim at identifying competing causes as such, and as a result a certain number of competing causes are missed, while at the same time conditions are coded which cannot be considered to be competing. For example, during routine coding Statistics Netherlands did not include diabetes mellitus among its multiple (non-underlying) cause codes if it concerned a case of non-insulin-dependent diabetes mellitus (diabetes mellitus type II) in a person 70 years or older. We did consider these forms of diabetes mellitus to be competing causes of death, because in the case of elimination of the underlying cause (e.g., ischemic heart disease) the presence of diabetes mellitus is likely to shorten life expectancy, for example by increasing the risk of cerebrovascular disease [23]. On the other hand, routine coding does assign multiple (non-underlying) cause codes to conditions which are frequently certified as "immediate" causes of death such as pneumonia and influenza. The net effect of all these under-and overestimations is that routine coding underestimates differences between underlying causes of death in the prevalence of competing causes. In our previous article we reported a $22 \%$ lower than average prevalence of competing causes among deaths from neoplasms [21]. Although this estimate was based upon information on a carefully selected subgroup of multiple causes only (after exclusion of "immediate" causes), the relative risk as obtained 
TABLE 3. Variation by main group of underlying cause of death in the prevalence of competing cause of death (The Netherlands, sample, 1990)

\begin{tabular}{|c|c|c|c|c|c|}
\hline \multirow[b]{2}{*}{ Competing cause of death } & \multicolumn{4}{|c|}{ RR $(95 \% \mathrm{CI})^{b}$ by underlying cause of death } & \multirow[b]{2}{*}{$\begin{array}{c}\text { Significance } \\
\text { level }\end{array}$} \\
\hline & $\begin{array}{c}\text { Neoplasms } \\
n=1797\end{array}$ & $\begin{array}{c}\text { Cardiovascular } \\
\text { diseases } \\
n=1793\end{array}$ & $\begin{array}{c}\text { Respiratory } \\
\text { diseases } \\
n=1196\end{array}$ & $\begin{array}{c}\text { Other } \\
\text { diseases } \\
n=1189\end{array}$ & \\
\hline Neoplasms & $\begin{array}{c}1.09 \\
(0.49-2.41)\end{array}$ & $\begin{array}{c}0.84 \\
(0.37-1.92)\end{array}$ & $\begin{array}{c}1.24 \\
(0.54-2.86)\end{array}$ & $\begin{array}{c}0.94 \\
(0.41-2.14)\end{array}$ & NS \\
\hline Diabetes mellitus & $\begin{array}{c}0.87 \\
(0.41-1.82)\end{array}$ & $\begin{array}{c}1.44 \\
(0.69-3.00)\end{array}$ & $\begin{array}{c}1.14 \\
(0.54-2.42)\end{array}$ & $\begin{array}{c}0.87 \\
(0.41-1.85)\end{array}$ & * \\
\hline Senile dementia & $\begin{array}{c}0.41 \\
(0.14-1.17)\end{array}$ & $\begin{array}{c}0.74 \\
(0.27-2.05)\end{array}$ & $\begin{array}{c}2.26 \\
(0.83-6.10)\end{array}$ & $\begin{array}{c}1.34 \\
(0.50-3.59)\end{array}$ & $*$ \\
\hline Alcoholism & $\begin{array}{c}0.21 \\
(0.09-0.49)\end{array}$ & $\begin{array}{c}1.14 \\
(0.70-1.88)\end{array}$ & $\begin{array}{c}1.44 \\
(0.79-2.62)\end{array}$ & $\begin{array}{c}1.42 \\
(0.95-2.11)\end{array}$ & $*$ \\
\hline Hypertensive disease & $\begin{array}{c}0.42 \\
(0.23-0.77)\end{array}$ & $\begin{array}{c}2.70 \\
(1.73-4.21)\end{array}$ & $\begin{array}{c}0.81 \\
(0.44-1.49)\end{array}$ & $\begin{array}{c}0.67 \\
(0.38-1.20)\end{array}$ & $* *$ \\
\hline Ischemic heart disease & $\begin{array}{c}0.71 \\
(0.41-1.21)\end{array}$ & $\begin{array}{c}0.53 \\
(0.31-0.94)\end{array}$ & $\begin{array}{c}1.07 \\
(0.62-1.85)\end{array}$ & $\begin{array}{c}1.50 \\
(0.92-2.43)\end{array}$ & ** \\
\hline Cerebrovascular disease & $\begin{array}{c}0.39 \\
(0.16-0.95)\end{array}$ & $\begin{array}{c}1.12 \\
(0.49-2.58)\end{array}$ & $\begin{array}{c}1.01 \\
(0.43-2.38)\end{array}$ & $\begin{array}{c}1.53 \\
(0.68-3.44)\end{array}$ & ** \\
\hline Arteriosclerosis & $\begin{array}{c}0.29 \\
(0.12-0.70)\end{array}$ & $\begin{array}{c}1.70 \\
(0.84-3.45)\end{array}$ & $\begin{array}{c}0.53 \\
(0.23-1.22)\end{array}$ & $\begin{array}{c}1.41 \\
(0.71-2.83)\end{array}$ & ** \\
\hline Other cardiovascular diseases & $\begin{array}{c}0.36 \\
(0.21-0.63)\end{array}$ & $\begin{array}{c}0.77 \\
(0.47-1.25)\end{array}$ & $\begin{array}{c}2.81 \\
(1.76-4.47)\end{array}$ & $\begin{array}{c}1.21 \\
(0.76-1.92)\end{array}$ & $* *$ \\
\hline Chronic obstructive lung disease & $\begin{array}{c}0.98 \\
(0.51-1.87)\end{array}$ & $\begin{array}{c}1.24 \\
(0.65-2.36)\end{array}$ & $\begin{array}{c}0.26 \\
(0.11-0.58)\end{array}$ & $\begin{array}{c}1.08 \\
(0.57-2.07)\end{array}$ & ** \\
\hline Nephritis and nephrosis & $\begin{array}{c}0.19 \\
(0.06-0.59)\end{array}$ & $\begin{array}{c}1.16 \\
(0.58-2.31)\end{array}$ & $\begin{array}{c}1.74 \\
(0.87-3.51)\end{array}$ & $\begin{array}{c}1.44 \\
(0.78-2.68)\end{array}$ & $* *$ \\
\hline All other diseases & $\begin{array}{c}0.47 \\
(0.37-0.59)\end{array}$ & $\begin{array}{c}1.00 \\
\left(\begin{array}{ll}0.82 & 1.22\end{array}\right)\end{array}$ & $\begin{array}{c}1.42 \\
(1.15-1.76)\end{array}$ & $\begin{array}{c}1.36 \\
(1.14-1.62)\end{array}$ & $* *$ \\
\hline All & $\begin{array}{c}0.54 \\
(0.47-0.62)\end{array}$ & $\begin{array}{c}1.08 \\
(0.95-1.22)\end{array}$ & $\begin{array}{c}1.42 \\
(1.25-1.62)\end{array}$ & $\begin{array}{c}1.27 \\
(1.13-1.43)\end{array}$ & $* *$ \\
\hline
\end{tabular}

Abbreviations: $\mathrm{CI}=$ confidence interval, $\mathrm{NS}=$ not significant, $\mathrm{RR}=$ relative risk.

${ }^{a}$ For ICD-9 codes, see Table 1 .

${ }^{b}$ Ratios of the prevalence in one underlying cause group and the prevalence in the whole sample, controlling for age and sex.

"Test based on teduction in scaled deviduce following introduction of "underlying cause of death" into a regression model already containing age and sex.

NS $=p \geq 0.05$

$p<0.05$.

$* 0<0.01$.

in our present study $(0.54$, Table 3$)$ corresponds to an even lower prevalence.

Although coding according to explicit rules is likely to have increased the validity of our findings, this validity ultimately depends upon the quality of the information present on death certificates. There are good reasons to believe in an underregistration of competing causes of dcath [24,25], both because of the lack of care with which these certificates are frequently completed, and because of the fact that the death certificate has never been designed to elicit explicit information on compering causes of death. It has been de- signed to identify the underlying cause of death, and information on other conditions is only asked for insofar as these contribute to death. Not all competing causes present at the time of dying may actually have contributed to death at that time, and physicians would be completely correct in not mentioning such a condition on the death certificate.

One finding which at first seems to be due to registration problems is that the observed prevalences do not rise after the age of 80 years (Figure 1). This stagnation contrasts with the conventional idea that co-morbidity increases steadily 
TABLE 4. Association between selected underlying and selected competing causes of death

\begin{tabular}{ll}
\hline $\begin{array}{l}\text { Underlying cause of death } \\
\text { with competing cause of death }\end{array}$ & RR (95\% CI) \\
\hline Lung cancer $(n=404)$ & \\
$\quad$ Ischemic heart disease & $1.14(0.59-2.18)$ \\
$\quad$ Chronic obstr. lung disease & $1.71(0.84-3.47)$ \\
Ischemic heart disease $(n=893)$ & $1.43(0.68-3.04)$ \\
$\quad$ Diabetes mellitus & $2.94(1.82-4.74)$ \\
$\quad$ Hypertensive disease & $1.40(0.59-3.27)$ \\
Cerebrovascular disease & $1.94(0.93-4.04)$ \\
Arteriosclerosis & $1.67(0.87-3.22)$ \\
Chronic obstr. lung disease & \\
Cerebrovascular disease ( $n=392)$ & $1.46(0.65-3.28)$ \\
$\quad$ Diabetes mellitus & $4.12(2.41-7.05)$ \\
Hypertensive disease & $2.24(1.23-4.08)$ \\
Ischemic heart disease & $2.31(1.03-5.19)$ \\
Arteriosclerosis & \\
Chronic obstructive lung disease $(n=717)$ & \\
Ischemic heart disease & $1.82(1.05-3.16)$ \\
\hline
\end{tabular}

${ }^{a}$ Ratios of the prevalence for the specific underlying cause and the prevalence in the whole sample, controlling for age and sex.

with age [26]. One explanation may be that physicians feel it is not necessary to provide an extensive explanation of the death of very old patients. However, both a British and an American study found that the completeness of registration of associated causes of death does not decrease with increasing age $[24,25]$. Therefore, the suggestion from our data that the prevalence of competing causes of death does not increase after the age of 80 years may be real, and deserves further study.

For the present study, the main concern is whether the degree of underreporting varies by underlying cause of death, because such differential underreporting would produce artificial associations between causes of death. We will discuss two possible cases.

Biological risk factors and precursors: The results from this study are in accordance with the expectation that, for example, deaths from ischemic heart disease show a relatively high prevalence of diabetes mellitus, hypertension, and arteriosclerosis. It may be suspected, however, that the reporting of these risk factors and precursors is more complete among ischemic heart disease deaths than among cancer deaths, for example, because physicians may be inclined to mention these conditions only when they are associated with the underlying cause of death and thus contributed to death. Therefore, death certificate data might overemphasize the strength of associations between some underlying causes of death and their risk factors and precursors.

Neoplasms as the underlying cause: The question should be addressed whether the most notable finding of our study, the low prevalence of competing causes among cancer deaths, is due to underreporting. It might be argued that co-morbidity among cancer deaths is underreported if certifiers feel that death from such a straightforward cause does not need an extensive justification. On the other hand, one could also argue that the extensive diagnostic procedures to which cancer patients are subjected will detect other disease which go unnoticed in patients dying from other underlying causes, such as an acute myocardial infarction. This issue remains a matter of speculation as long as studies of the validity of death certificate data on competing causes of death are not carried out.

Thus, the possibility cannot be excluded that some of the observed associations can in part be attributed to differential underregistration of competing causes of death. Results have to be interpreted with caution as long as studies of the validity of death certificate data on competing causes of death are not carried out. Despite these reservations, however, a number of associations between specific underlying causes and specific competing causes as reported in this article (Table 4) is difficult to attribute to differential underreporting, and suggests that there also may be some truth in the overall patterns.

The existence of associations between competing causes of death has major implications for estimates of the potential mortality effect of ongoing or planned health care and public health interventions. Among persons that would be saved by such interventions the prevalence of competing causes is likely to be higher than among the general population, because of the many interrelationships between different conditions. Unfortunately, we have no good data on the prevalence in the general population of the conditions studied as competing causes in this article, so that a direct comparison is impossible. Nevertheless it is probably wise to consider all conventional estimates of gains in life expectancy after elimination of a certain underlying cause of death as overestimates of the gains in life expectancy which can truly be expected.

Equally important, however, is the fact that the degree of overestimation is likely to be different between underlying causes of death. The results of our study suggest that the prevalence of competing causes differs substantially between neoplasms, cardiovascular diseases, and respiratory diseases as underlying causes of death. These differences imply that conventional estimates of gains in life expectancy after elimination of respiratory diseases are overestimated to a larger extent than gains in life expectancy after elimination of cardiovascular diseases, while the latter are more overestimated than gains in life expectancy after elimination of neoplasms. These conventional estimates therefore are likely to produce a seriously biased picture of the relative importance of inteventions against neoplasms, cardiovascular diseases, and respiratory diseases, respectively.

This study was financially supported by the Ministry of Public Health, Welfare and Sports. 


\section{References}

1. Chiang CL. Competing risks in mortality analysis. Annu Rev Publ Health 1991; 12: 281-307.

2. Chiang CL. Introduction to Stochastic Processes in Biostatistics. New York: John Wiley \& Sons; 1968.

3. Keyfitz N. What difference would it make if cancer were eradicated? An examination of the Taueber paradox. Demography 1977; 14: 411-418.

4. Tsai SP, Lee ESL, Hardy RJ. The effect of a reduction in leading causes of death: Potential gains in life expectancy. Am J Public Health 1978; 68: 966-971.

5. Cornfield J. The estimation of the probability of developing a disease in the presence of competing risks. Am J Public I lealth $1957 ; 47$ : 601-607.

6. Prentice RL, Kalbfleisch JD, Peterson AV, et al. The analysis of failure times in the presence of competing risks. Biometrics 1978; 34: 541-554.

7. Manton KG, Tolley DH, Poss SS. Life table techniques for multiple-cause dara. Demography 1976; 13: 541-564.

8. Wong $\mathrm{O}$. A competing risk model based on the life table procedure in epidemiological studies. Int J Epidemiol 1977; 6: 153-159.

9. Manton KG, Poss SS. Effects of dependency among causes of death for cause elimination life table strategies. Demography 1979; 16: 313-327.

10. Manton K, Stallard E. Recent Trends in Mortality Analyses. New York: Academic Press; 1986.

11. Israel RA, Rosenberg HM, Curtin LR. Analytical potential for multiple cause-of-death data. Am J Epidemiol 1986; 124: $161-179$.

12. Puffer RR. New approaches for epidemiologic studies of mortality statistics. Bulletin of PAHO 1989; 23: 365-383.

13. Park CB, Yokoyama E, Tokuyama GH. Medical conditions at death among the Caucasian and Japanese elderly in Hawaii: Analysis of multiple causes of death, 1976-78. J Clin Epidemiol 1991; 44: 519-530.

14. Steenland K, Nowlin S, Ryan B, Adams S. Use of multiplecause mortality data in epidemiologic analysis: U.S. rate and proportion files developed by the National Institute for Occu- pational Safety and Health and the National Cancer Institute. Am J Epidemiol 1992; 136: 855-862.

15. White MC, Selvin S, Merrill DW. A study of multiple causes of death in California: 1955 and 1980. J Clin Epidemiol 1989; 42: 355-365.

16. Mackenbach JP. Secundaire doodsoorzaken. Tijdschr Soc Gezondheidsz 1987; 65: 524-528.

17. Manton KG, Stallard E. Temporal trends in U.S. multiple cause of death mortality data: 1968 to 1977. Demography 1982; 19: 527-547.

18. Manton KG. Cause specific mortality patterns among the oldest old: Multiple cause of death trends 1968 to 1980 . J Gerontol 1986; 41: 282-289.

19. Wing S, Manton KG. $\Lambda$ multiple cause of death analysis of hypertension-related mortality in North Carolina, 19681977. Am J Public Health 1981; 71: 823-830.

20. Manton KG. Sex and race specific mortality differentials in multiple cause of death data. Gerontologist 1980; 20: 480493.

21. Mackenbach JP, Kunst AE, Lautenbach H, Bijlsma F, Oei YB. Competing causes of death: An analysis using multiple-causeof-death data from the Netherlands. Am J Epidemiol 1995; 141: 466-475.

22. World Health Organization. Manual of the International Statistical Classification of Diseases, Injuries and Causes of Death, 9th Revision. Geneva: World Health Organization; 1977.

23. Koskinen SV, Martelin TP, Valkonen T. Socioeconomic differences in mortality among diabetic people in Finland: Fiveyear follow-up. BMJ 1996; 313: 975-978.

24. Bild DE, Stevenson JM. Frequency of recording of diabetes on U.S. death certificates: Analysis of the 1986 national mortality followback survey. J Clin Epidemiol 1992; 45: 275-281.

25. Goldacre MJ. Cause-specific mortality: Understanding uncertain tips of the disease iceberg. J Epidemiol Comm Health 1993; 47: 491-496

26. Schellevis FG, van der Velden J, van de Lisdonk E, et al. Comorbidity of chronic diseases in general practice. J Clin Epide. miol 1993; 46: 469-473. 